\title{
Upper and lower blepharoplasty technique associated with canthopexy with double pre septal orbicularis muscle elevation with a single suture
}

\author{
Blefaroplastia superior e inferior associada à cantopexia com elevação \\ dupla de músculo orbicular pré-septal em sutura única
}

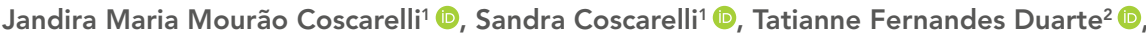
Juliana Senna Figueiredo Barbi² ${ }^{\mathbb{D}}$, Kimberly Marie Jones ${ }^{3}$ (D)

Clínica de Olhos Ennio Coscarelli, Belo Horizonte, MG, Brazil. ${ }^{2}$ Hospital de Olhos Hilton Rocha, Belo Horizonte, MG, Brazil.

${ }^{3}$ Kennedy and Promove University, Belo Horizonte, MG, Brazil.

Blepharoplasty/adverse effects;

Canthopexy; Ligaments/ pathology; Eyelid diseases;

Aging

Descritores:

Blefaroplastia/efeitos adversos;

Cantopexia; Ligamentos/

patologia; Doenças palpebrais; Envelhecimento

Received on: May 25,2021

Accepted on: Oct 6, 2021

Corresponding author: Juliana Senna Fiqueiredo Barbi Rua Groelândia, 135 - Sion. Zip code: 30320-060 - Belo Horizonte, MG, Brazil

E-mail: drajulianabarbi@gmail.com Institution: Hilton Rocha Hospital. Belo Horizonte, MG, Brazil.

Conflict of interest: no conflict of interest.

Financial support: the authors received no financial support for this work.

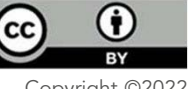

Copyright (C)2022

\section{ABSTRACT}

Objective: To describe the upper and lower blepharoplasty technique associated with canthopexy with double pre septal orbicularis muscle elevation with a single suture in order to evaluate the efficacy of the technique.

Methods: This is a retrospective study in which the medical records of 5,882 patients who underwent this technique between January 1999 and July 2015 were evaluated. The frequency and main causes of clinical complications and surgical reoperation were analyzed.

Results: The incidence of complications found was $12.7 \%(n=750)$, being $0.8 \%$ ( $n=47)$ due to persistent chemosis, 3\% $(n=176)$ due to poor lower eyelid positioning, 4.17\% $(n=245)$ due to mild eyelid retraction and $4.8 \%(n=282)$ because of mild to moderate chemosis

Conclusion: The technique appears to be effective as it is simple and practical, and capable of resulting in positive functional and aesthetic outcomes with low rates of complications.

\section{RESUMO}

Objetivo: Descrever a técnica de blefaroplastia superior e inferior associada à cantopexia associada à dupla elevação do músculo orbicular pré-septal em uma única sutura e avaliar sua eficácia.

Métodos: Trata-se de estudo retrospectivo, no qual foram avaliados 5.882 prontuários de pacientes submetidos à blefaroplastia superior e inferior com a utilização da cantopexia, entre janeiro de 1999 e julho de 2015. Taxas e principais causas de complicações clínicas e reintervenção cirúrgica foram analisadas.

Resultados: A incidência de complicações encontradas foi de $12,7 \%(n=750)$, sendo $0,8 \%(n=47)$ de caso de quemose persistente, $3 \%(n=176)$ de mau posicionamento palpebral inferior (ectrópio), 4,17\% ( $n=245)$ de leve retração pálpebra e 4,8\% ( $n=282)$ de quemose leve a moderada.

Conclusão: A técnica mostra-se eficaz por ser simples e prática, podendo ter resultados funcionais e estéticos positivos e com baixo índice de complicações. 


\section{INTRODUCTION}

Aging of the periorbital region causes significant changes in facial anatomy, most notably protrusions of orbital fat pads, eyelid ligament sagging, fixed wrinkles called expression lines and the loss of the physiological contour of the periocular region leading to the appearance of a "tired look". ${ }^{(1,2)}$ In this context, blepharoplasty has become one of the most requested procedures performed by plastic and oculoplastic surgeons and is generally the first aesthetic surgical procedure sought by patients on the face.

Given the anatomical peculiarities of the eyelid region, lower transcutaneous blepharoplasty surgery may induce a scarring process that can lead to undesirable postoperative anatomical alterations such as apparent sclera, as well as rounding of the lateral palpebral corner and ectropium. (3-5) Advances in studies on the aging process have considered structural changes in bone reabsorption, the roles of adipose tissue and collagen, and the importance of lateral canthal ligament in eyelid support. ${ }^{(6,7)}$ These studies have led to important advances in surgical techniques geared towards facial and periorbital rejuvenation..$^{(8,9)}$

The aim of this study is to describe the functional and aesthetic outcomes in upper and lower blepharoplasty using a canthopexy with double pre-septal orbicularis muscle elevation in a single suture, considering the rates of postoperative complications and reoperation.

\section{METHODS}

This is a retrospective study in which the medical records of 5,882 patients who underwent the surgical procedure described during the period January 1999 to July 2015. All surgeries were performed by the same surgeon, using the Loktal 5000 radiofrequency device, having standardized it in cutting mode (for skin incision) and in blend mode (for tissue dissection). Surgical wires of the same brand were used for both canthopexy and for skin closure of all patients submitted to this technique.

The surgeries were individualized regarding the removal or maintenance of fat pads or other procedures deemed necessary, such as correction of aponeurotic ptosis and trichiasis.

Photo documentation was performed by the same professional, following the same photographic parameters of aperture, shutter speed and ISO, in addition to the same preoperative and postoperative periods ( 6 months postoperative). The rates and main causes of clinical complications and surgical reintervention were analyzed.

All patients were invited to sign the voluntary and Informed Consent Form and authorized the use of their images in scientific publications. The study was conducted in accordance with the Declaration of Helsinki Ethical Principles after being approved by the Institutional Review Board (protocol 41062920.9.0000.5141 of Associação Educativa do Brasil / Faculdades Unidas do Norte de Minas).

\section{Surgical technique}

Initially, classical upper blepharoplasty is performed via a skin incision along a marked area, followed by skin resection. After homeostasis of the orbicularis oculi muscle bed is achieved, resection of the preseptal orbicularis oculi muscle is performed, and the prominent fat pads are excised, after which homeostasis is once again assessed. During the entire procedure, a radiofrequency device is used in the cutting mode (80\% cutting and 20\% coagulation) for skin incisions and in the blend mode (50\% cutting and 50\% coagulation) for tissue dissection.

For lower blepharoplasty, a skin incision is made at the previously marked incision site with the radiofrequency device in the cutting mode. It is critical to note that while performing sub ciliary incision, the skin is detached up to the lower portion of the pretarsal orbicularis muscle (Figure 1A) to allow resection of the myocutaneous flap (Figure $1 \mathrm{~B}$ ); the excessive skin and preseptal orbicularis muscle are completely resected as a myocutaneous flap, using the radiofrequency device in the blend mode. The prominent fat pads are then excised and homeostasis is reassessed.

The border of the superolateral orbital rim is first palpated through the external corner of the upper eyelid. The incision is made in the orbital septum at approximately $5 \mathrm{~mm}$ to $7 \mathrm{~mm}$ to expose the white region, which corresponds to the lateral canthal tendon (Figure 1C). A prolene 5-0 suture needle is passed under the tendon (Figure 1D) and outward through the lower border of the pretarsal orbicularis muscle at the same height of the eyelid lateral angle (Figure 1E). The pre septal orbicularis muscle is then identified and fixed by moving the needle in the opposite direction (towards the upper eyelid) (Figure $1 \mathrm{~F}$ ). Before entering the tunnel (below the lateral canthal tendon), the needle is introduced between the pretarsal orbicularis muscle and inferior tarsus, then rotated $180^{\circ}$ so that it can be observed at the corner of the eyelid. Then, the needle is inserted into the tunnel again and removed via the entrance site (Figure $1 G$ ). Subsequently, the needle is fixed in the periosteum of the upper-lateral orbital rim (Figure $1 \mathrm{H}$ ), and three knots are tied (Figure 1I). To ensure a better esthetical outcome, the needle is once again introduced into the tunnel, 

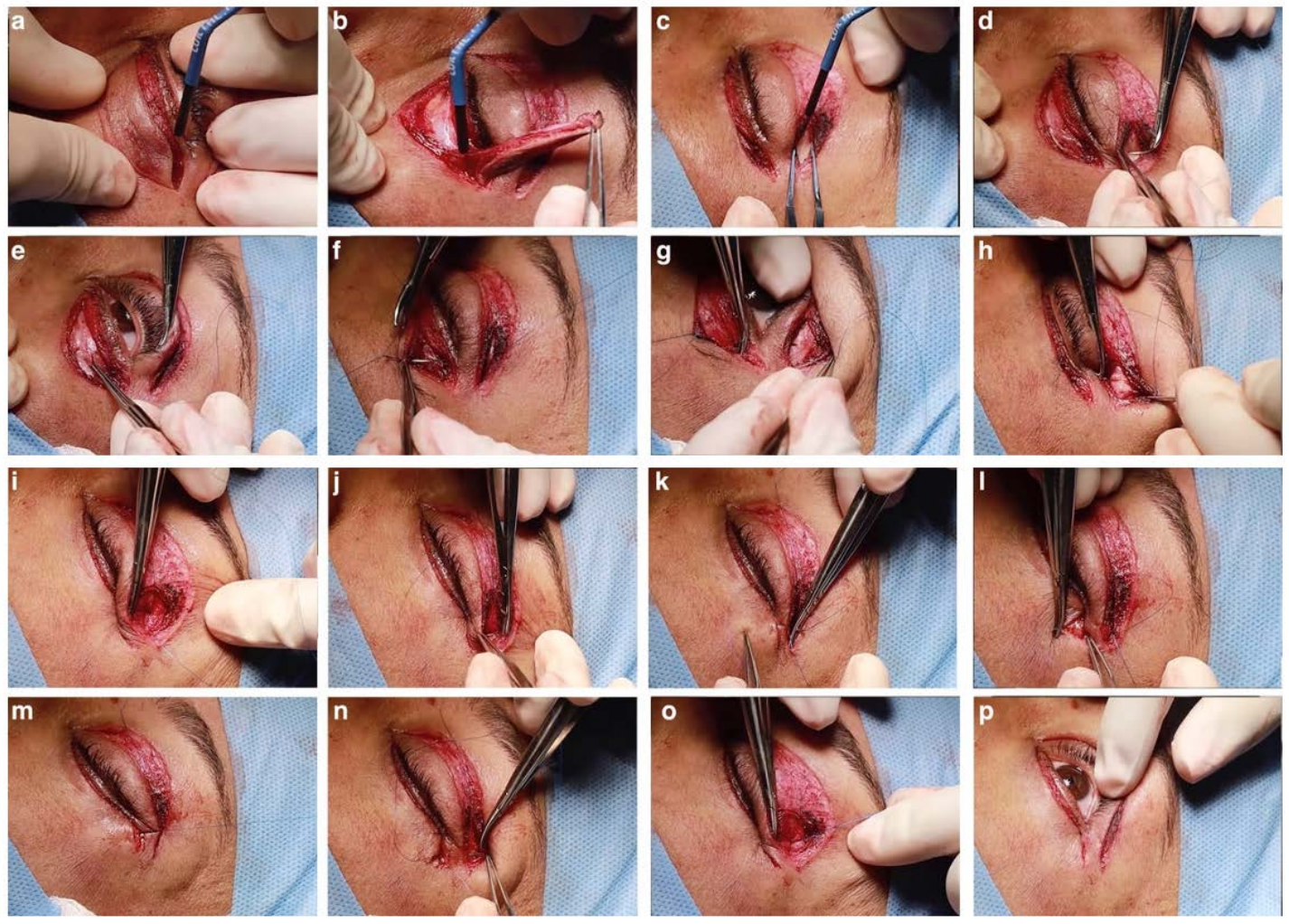

Figure 1. Surgical technique. (A) Lower blepharoplasty skin removal. The skin is detached up to the lower portion of the pretarsal orbicularis muscle. (B) Resection of the myocutaneous flap. Excessive skin and preseptal orbicularis muscle are completely resected using the radiofrequency device in the blend mode. (C) Incision in the orbital septum at the upper-lateral orbital rim to expose the white region, which corresponds to the lateral canthal tendon. (D) A prolene 5-0 suture needle transfixes the tendon, passing under it. (E) The needle is inserted outward through the lower border of the pretarsal orbicularis muscle at the same height of the eyelid lateral canthus. (F) The pre septal muscle is identified and fixed by moving the needle in the opposite direction (towards the upper eyelid). (G) Before entering the tunnel (below the lateral canthal tendon), the needle is introduced between the pretarsal orbicularis muscle and inferior tarsus and rotated $180^{\circ}$ prior to being reinserted into the tunnel (under lateral canthal tendon) and being removed via the entrance site. $(\mathrm{H})$ The suture is fixed in the periosteum of the upper-lateral orbital rim. (I) Three knots are tied. Notice that the knot is buried just to the periosteum, underneath the orbicularis muscle that is isolated at the time of suture, to avoid trapping its fibers with the suture. $(\mathrm{J})$ The needle is again introduced in the tunnel, but this time in a more lateral position compared to the first knot. $(K)$ The needle penetrates the submuscular space to the topography of the upper border of the superficial musculo-aponeurotic system, shown by the tweezer in the figure. (L) Plicature of pre septal orbicularis muscle in a lateral position. (M) Pre septal orbicularis muscle elevation shown by the skin traction. (N) The needle is again introduced in the tunnel, in a more lateral position compared to the first knot, without fixing the periosteum. (O) Another knot is tied, lying internal do the septum. (P) The final aspect without a skin suture showing, and featuring the correct positioning of skin and muscles without any traction.

but this time in a more lateral position, compared to the first knot (Figure 1J), so that the lateral border of pre septal orbicularis muscle (Figure $1 \mathrm{~K}$ ) is fixed (Figures $1 \mathrm{~L}$ e $1 \mathrm{M})$. The needle is then returned to the site where the suture was introduced (Figure $1 \mathrm{~N}$ ), and, finally, a knot is once again tied (Figure 1O). The suture end, lying internal to the septum, is then cut (Figure 1P).

\section{RESULTS}

The technique described by the authors was performed in 5,882 patients from January 1999 to December 2015.
$87.6 \%(\mathrm{n}=5,153)$ of the patients were female and $12,4 \%$ $(\mathrm{n}=729)$ male. Their ages ranged from 37 to 86 -years-old with a mean of 56 years. The selected patients presented mild to moderate eyelid sagging (distraction test between $3 \mathrm{~mm}$ to $5 \mathrm{~mm}$ ), upper and lower dermatochalasis (associated or not with prominent fat pads). The incidence of complications found was $12.7 \%(\mathrm{n}=750)$, being $0.8 \%$ $(\mathrm{n}=47)$ due to persistent chemosis, $3 \%(\mathrm{n}=176)$ due to poor lower eyelid positioning, $4.17 \%(n=245)$ due to mild eyelid retraction and $4.8 \%(n=282)$ because of mild to moderate chemosis as shown in Figure 2. 


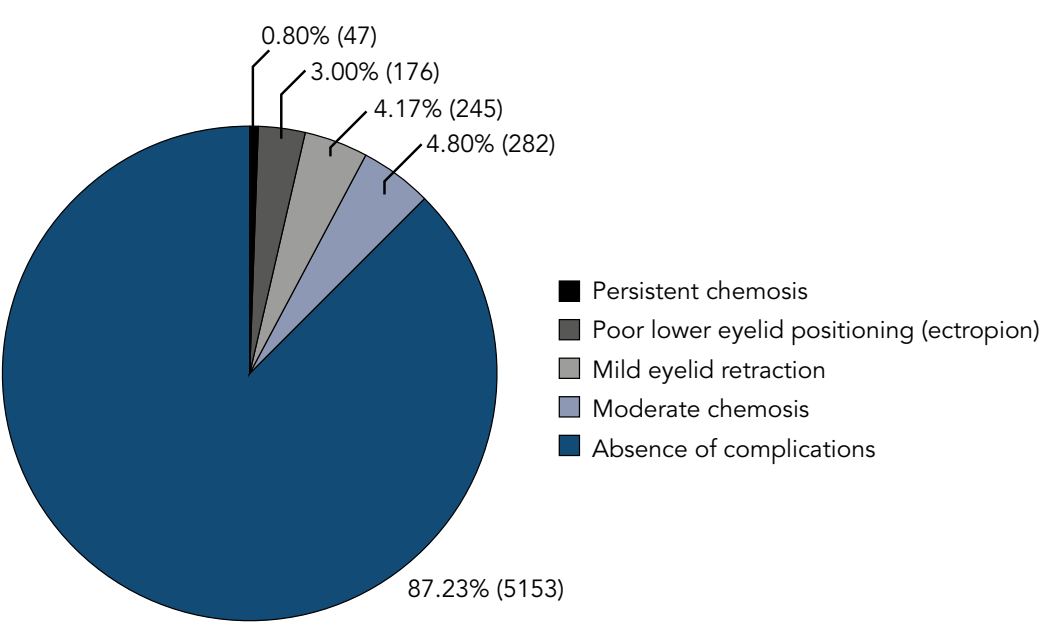

Figure 2. Complication rates in absolute numbers and percentages within the study sample.

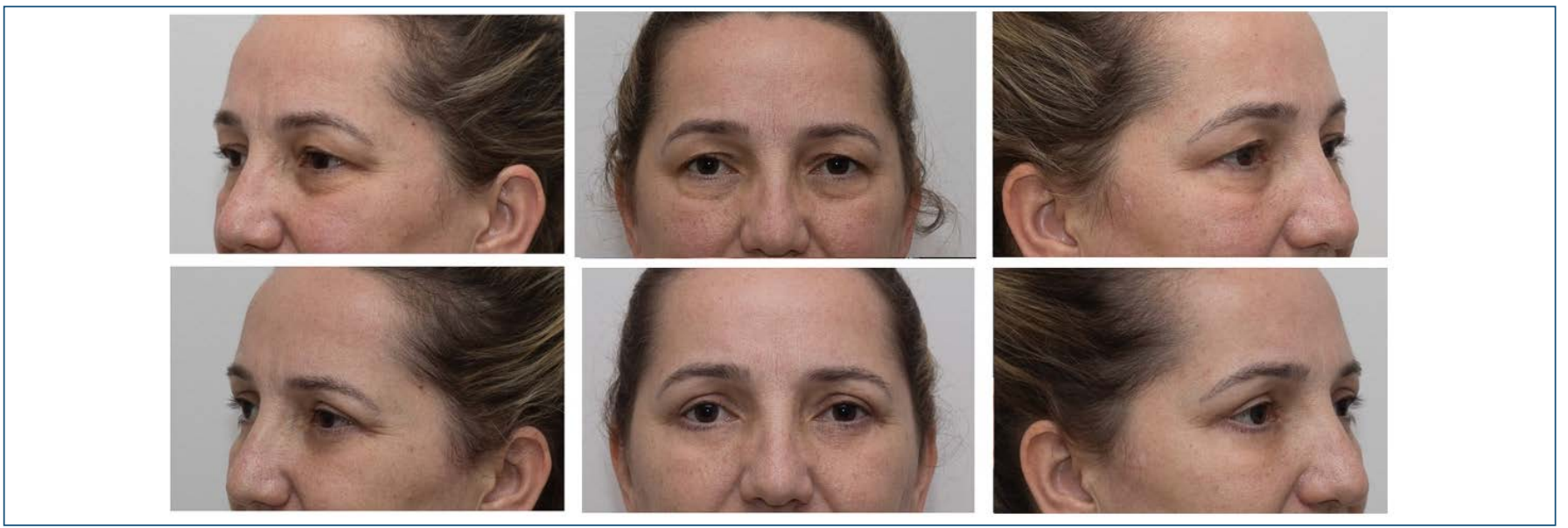

Figure 3. Preoperative (upper line) and 6-month postoperative (lower line) photos of a 55-year-old, female patient submitted to upper and lower blepharoplasty with a canthopexy technique in primary position of gaze and right and left oblique views.

Figure 3 shows preoperative photos (upper line) and 6 -month postoperative (lower line) photos of a 55-yearold female patient submitted to upper and lower blepharoplasty with the canthopexy described.

\section{DISCUSSION}

Previous studies have described a wide range in the percentage of complications ( $5 \%$ to $90 \%$ ), principally due to poor positioning of the eyelids resulting from lower eyelid blepharoplasty. ${ }^{(9,10)}$ Vertical deficiency of the anterior lamella (skin) and fibrosis that occurs in medial and posterior lamella, associated with lateral canthal tendon laxity, are among the most common etiological factors in the poor positioning of lower eyelids. ${ }^{(11)}$

Different techniques have been described aiming to minimize the undesirable effects of inferior blepharoplasty on eyelid positioning. Initially described by Jelks et al., ${ }^{(12)}$ lower lateral retinal cantoplasty with upper blepharoplasty incision can be performed both in conjunction with transconjunctival and transcutaneous inferior blepharoplasty. Lateral canthal tendon lysis may or may not be associated with considering the need for horizontal shortening of the lower eyelid. Modified by Lessa et al. ${ }^{(13)}$ canthopexy without canthotomy is related to cases of moderate lower palpebral sagging in patients undergoing transconjunctival blepharoplasty, when there is no indication of a horizontal shortening of the bottom of the eyelid.

Mitz et al. ${ }^{(6)}$ emphasize the importance of the SMAS approach in complementing blepharoplasty and supporting techniques of the masseteric-zygomatic region, thus removing part of the skin tension of the periorbital region. This technique was later addressed by Ress et al. ${ }^{(7)}$ in clinical studies with high success rates. Transcutaneous inferior blepharoplasty may present good aesthetic results by reducing excess eyelid skin resulting in virtually 
imperceptible scars, however, it can lead to eyelid retraction at an incidence of $15 \%$ to $20 \% .^{(12,14,15)}$

The authors describe upper and lower blepharoplasty technique associated with canthopexy with double pre septal orbicularis muscle elevation with single suture in selected patients who presented dermatochalasis and fat pads. It was observed in this study that the double elevation of the preseptal orbicularis muscle and fixing it on the superolateral orbital rim decreases the vertical tension on the lower eyelid. In addition, the reinforcement of the lateral canthal ligament provided adequate eyelid positioning, opposing healing forces.

The low surgical reintervention rate $(3 \%)$ in the present study points to the great safety and predictability of the technique since primary failure occurred due to problems inherent to suture dehiscence or loosening, a complication that can be avoided when paying attention to the correct knot of the wire and avoiding cauterization of tissues near the place of passage of the canthopexy suture. In these cases, a new surgical approach was performed, noting intraoperatively that, in cases of ectropion, the causal factor was suture dehiscence. Therefore, these patients were submitted to a new canthopexy suture, performed similarly, observing the tension of the prolene 5.0 thread in the intraoperative period with a total resolution of the clinical picture 6 months after this second surgical approach.

Macedo et al..$^{(15)}$ and collaborators compare the lower blepharoplasty technique associated with lateral canthopexy with isolated lower blepharoplasty and observed a 1\% scar retraction index contrasting with $16 \%$ respectively. It is important to note that, although lateral canthal tendon canthopexy is efficient in most cases, some situations of important ligament laxity with lentificated Snapback test or Distraction test greater than $6 \mathrm{~mm}$ may require canthoplasty at the rather than only canthopexy even in primary lower blepharoplasty.

In our series, chemosis was the most common complication totaling $5.6 \%(n=329)$ of the total number of patients, followed by mild eyelid retraction and ectropion. The complications found are within the indexes published in the international literature and were subject to clinical or surgical correction. Some limitations present in this article were the non-application of a postoperative satisfaction questionnaire that would allow a better understanding of results in quality of life and self-esteem routinely experienced by patients undergoing surgeries of aesthetic-functional scope.

Patients who developed postoperative chemosis were treated conservatively, with nocturnal eyelid occlusion and daytime use of eye drops with steroids and lubricants, resulting in a satisfactory resolution of cases. Patients who developed eyelid retraction were instructed to do local massage, and most presented complete improvement of their condition in the third month after surgery. However, for 18 patients did not improve retraction with three months of massage, we chose to inject 3mg of triamcinolone in the submuscular (suborbicular) plane at the retraction site, resulting in good responses after 6 months of follow-up.

\section{CONCLUSION}

The suture method described above allows for the improvement of the eyelids since the procedure involves reinforcement of the lateral canthal tendon associated with double elevation of pre septal orbicularis muscle. The technique described above results in esthetically and functional pleasing outcomes, with good positioning of all structures, including accurate circumscription of the borders of the skin incision required for lower blepharoplasty. Therefore, the adaptation of this technique may be advisable due to its simplicity and the frequency of clinically satisfactory results.

\section{REFERENCES}

1. Rohrich RJ, Pessa JE. The fat compartments of the face: anatomy and clinical implications for cosmetic surgery. Plast Reconstr Surg. 2007;119(7):2219-27

2. Ghavami A, Pessa JE, Janis J, Khosla R, Reece EM, Rohrich RJ. The orbicularis retaining ligament of the medial orbit: closing the circle. Plast Reconstr Surg. 2008;121(3):994-1001.

3. Viana GA, Osaki MH, Nishi M. [Lower blepharoplasty: would the surgery provide satisfaction to the patient?]. Arq Bras Oftalmol. 2012;75(6):402-6. Portuguese.

4. Basile F. Correction of eyelid tracts secondary to blepharoplasty. Rev Bras Cir Plást. 2011;26(2):228-42

5. McGraw B, Adamson P. Post blepharoplasty ectropion: Prevention and management. Arch Otolaryngol Head Neck Surg. 1991;117(8):852-7.

6. Mitz V, Petronius M. The superficial musculo-aponeurotic system (SMAS) in the parotid and cheek area. Plastic Reconstr Surg. 1976;58(1):80-8.

7. Ress T, Aston S. A clinical evaluation of the results of submusculoaponeurotic dissection and fixation in face lifts. Plast Reconstr Surg. 1997;60(6):851-9.

8. Baek JS, Kim KH, Lee JH, Choi HS. Ophthalmologic complications associated with oculofacial plastic and esthetic surgeries. J Craniofac Surg. 2018;29(5):1208-11.

9. Andretto Amodeo C, Casasco A, Icaro Cornaglia A, Kang R, Keller GS The suborbicularis oculi fat (SOOF) and the fascial planes: has everything already been explained? JAMA Facial Plast Surg. 2014;16(1):36-41.

10. Vieira R, Pinho A, Brinca A. Repair of the lower eyelid with primary closure with lateral canthopexy and elevation of the suborbicularis oculi fascia: a simple technique to avoid post-operatory ectropion. Surg Cosmet Dermatol. 2018;(10):346-8.

11. Khan M, Aziz K, Javed A, Gorman M, Othman D, Riaz M. Modified lower eyelid blepharoplasty improves aesthetic outcomes in patients with hypoplastic malar prominences. Plast Aesthet Res. 2017;4:22835 . 
12. Jelks $G$, Glat $P$, Jelks $E$, Longaker $M$. The inferior retinacular lateral canthoplasty: A new technique. Plast e Reconstr Surg. 1997;100(5):1262 70

13. Lessa S, Sebastiá R, Flowers E. A simple cantopexia. Rev Bras Oftalmol. 1999;58(10):779-86
14. Oestreicher J, Mehta S. Complications of blepharoplasty: prevention and management. Plast Surg Int. 2012;2012:252368.

15. Macedo J, Person S, Person B, Almeida G, Oliveira N, Gomes A. Cantopexia lateral as a primary procedure in lower blepharoplasty. Rev Bras Cir Plast. 2009:24(1):30-5. 